\title{
IMPACTOS DA EXPANSÃO DO AGRONEGÓCIO BRASILEIRO NA CONSERVAÇÃO DOS RECURSOS NATURAIS
}

\author{
Cecília Siman Gomes ${ }^{1}$
}

\begin{abstract}
Resumo:
O agronegócio possui papel fundamental na economia brasileira, mas seu desenvolvimento é acompanhado por crescentes preocupações com os impactos ambientais provocados pela agricultura e pecuária nos recursos naturais, que podem repercutir na biodiversidade, na disponibilidade hídrica, na qualidade do ar e do solo e na saúde humana. Nesse contexto, o objetivo geral desse artigo é analisar a atuação do agronegócio brasileiro e os impactos ambientais provocados pelo seu modelo de produção. Para tanto, foi feito um levantamento bibliográfico em artigos científicos, teses, dissertações, manuais e documentos governamentais que tratam do tema em questão. Pode-se dizer que o processo de modernização e expansão do setor agropecuário no Brasil impulsionou a sua produtividade, no entanto, provocou impactos negativos para o meio ambiente, tais como a erosão e contaminação dos solos, do ar e das águas, sobretudo através de técnicas convencionais utilizadas nas monoculturas, a inserção de plantas transgênicas e o uso cada vez maior de insumos agrícolas. O custo ambiental gerado pelo agronegócio não é computado na sua produção e, em longo prazo, poderemos ter perdas ambientais irremediáveis. Dessa forma, é fundamental e urgente repensar o modelo de desenvolvimento tecnológico que vem sendo adotado pelo agronegócio brasileiro.
\end{abstract}

Palavras chaves: agronegócio, recursos naturais, impactos ambientais.

\begin{abstract}
The agribusiness has a fundamental role in the Brazilian economy, but its development is accompanied by growing concerns about the environmental impacts of agriculture and livestock on natural resources, which can have an impact on biodiversity, water availability, air and soil quality, and in human health. In this context, the general objective of this article is to analyze the performance of Brazilian agribusiness and the environmental impacts caused by its production model. For that, a bibliographical survey was made in scientific articles, theses, dissertations, manuals and governmental documents that deal with the subject in question. It can be said that the process of modernization and expansion of the agribusiness sector in Brazil has increased its productivity; however, it has caused negative impacts to the environment, such as erosion and contamination of soils, air and water, especially through conventional techniques used in monocultures, the insertion of transgenic plants and the increasing use of pesticides input. The environmental cost generated by agribusiness is not computed in its production and, in the long term, we may have irreparable environmental losses. Thus, it is fundamental and urgent to rethink the technological development model that has been adopted by Brazilian agribusiness.
\end{abstract}

Key-Words: agribusiness, natural resources, environmental impacts.

${ }^{1}$ Universidade Federal de Minas Gerais - Doutoranda em Geografia - ceciliasiman@gmail.com 


\section{1 - INTRODUÇÃO}

O agronegócio, expressão tradicionalmente conhecida pelo termo em inglês agribusiness, compreende toda a cadeia produtiva da agricultura e pecuária, englobando desde a fabricação dos insumos essenciais, a produção e os procedimentos envolvidos, até o consumo final dos produtos agropecuários (BIALOSKORSKI NETO, 1994). Nessa cadeia, diversos são os serviços desenvolvidos: pesquisa, processamento, comercialização, exportação, distribuição, consumidor, entre outros. (CONTINI et al., 2006). Assim, consiste em grandes negócios no setor da agropecuária.

O agronegócio possui papel fundamental na economia brasileira, pois gera emprego e renda, apresenta papel ativo no saldo positivo da balança comercial brasileira e destaca o país no comércio internacional. O Brasil é o terceiro maior exportador de commodities $^{2}$, sendo o primeiro em açúcar, café, suco de laranja, carne bovina e de frango (ASSAD et al., 2012). Também é um dos maiores produtores agrícolas do mundo, e em 2019 passará a liderar a produção mundial de soja.

Além disso, o Brasil tem sido considerado como um dos principais países produtores de agrocombustíveis, como a cana-de-açúcar, a mamona, a própria soja, o óleo de palmas, entre outros, que servem como matéria-prima para a produção do etanol e do biodiesel. No mundo, a área total cultivada com matérias-primas para os agrocombustíveis em 2008 foi estimada em 36 milhões de hectares, duas vezes mais que em 2004. Deste total, 8,3 milhões de hectares localizamse na União Europeia, com cultivo de canola; 7,5 milhões, nos Estados Unidos, com lavouras de milho; e 6,4 milhões de hectares estão na América Latina, primordialmente com cultivos de cana no Brasil (BANCO MUNDIAL, 2010). Ainda conforme o Banco Mundial (2010), a maior participação brasileira de agrocombustíveis no mercado mundial se dá fundamentalmente na produção de milho, soja e cana-de-açúcar.

Em função da relevância do agronegócio para a economia brasileira, o agronegócio é o principal receptor de investimentos do governo, o que incentiva a expansão do mercado de novas tecnologias de monoculturas. O desenvolvimento do setor, porém, é acompanhado por crescentes preocupações com os impactos ambientais provocados pela agricultura e pecuária, principalmente quanto ao consumo de água, aplicação de agrotóxicos e fertilizantes, emissão de gás metano, desmatamento e queimadas de vegetação nativa para expansão do agronegócio (ASSAD et al., 2012).

\footnotetext{
${ }^{2}$ As commodities - ou commodity, no singular - é uma expressão do inglês que faz referência a um determinado bem ou produto, de origem primária, comercializado em grande quantidade, em escala mundial. Seu preço é regulado pela sua cotação no mercado e não pela sua produção.
} 
Assim, os avanços obtidos pelo agronegócio vêm produzindo diversos riscos e impactos nos recursos naturais, notadamente no solo, nas águas e no ar, que podem repercutir na biodiversidade, na disponibilidade hídrica, na qualidade do ar e do solo e na saúde humana. Nesse contexto torna-se necessário avançar nas discussões de como o agronegócio vem atuando no Brasil ao longo do tempo, avaliando os impactos negativos associados as suas atividades. Dessa forma, o objetivo geral desse artigo é analisar a atuação do agronegócio brasileiro e os impactos ambientais provocados pelo seu modelo de produção.

Para tanto, foi feito um levantamento bibliográfico em artigos científicos, teses, dissertações, manuais e documentos governamentais que tratam do tema em questão. Com base na coleta de dados e informações, foi feita inicialmente uma contextualização da expansão do agronegócio brasileiro, abarcando as regiões de expansão agrícola, as condições favoráveis à expansão, áreas de vegetação suprimidas, o mercado da soja, dados de produtividade e projeções futuras.

Em sequência foram investigados quais impactos são esperados nos recursos naturais, sobretudo no solo e na água, decorrentes do modelo de produção do agronegócio. Também é exposto como impactos de primeira ordem podem afetar tanto a biota quanto a saúde humana. Nessa etapa ainda foi feita uma investigação da situação atual brasileira, considerando dados e aspectos do agronegócio envolvidos na produção de impactos e riscos ambientais nos recursos naturais.

Por fim, foi feita uma análise da conjuntura atual brasileira, tecendo considerações sobre a necessidade de ser repensar novos modelos de produção agropecuária para reduzir impactos e perdas ambientais.

\section{2 - A EXPANSÃo DO AGRONEGÓCIO NO BRASIL E TENDÊNCIAS FUTURAS}

A expansão do agronegócio no Brasil ocorreu a partir das décadas de 1950 e 1960, principalmente nas regiões sul e sudeste e, a partir de 1970, para outras regiões (PLATA e CONCEIÇÃO, 2012), com destaque para a região de Cerrado do centro oeste. A ocupação desta região se deu, sobretudo, a partir da evolução tecnológica das culturas, que permitiu a adaptação de produtos agrícolas ao clima tropical, o aumento da produtividade, a resistência a pragas (doenças, insetos-praga e plantas daninhas) e a mecanização das culturas (GAZZONI, 2013). Pode-se dizer que a década de 1970 marcou a modernização da agricultura, transformando o Cerrado, terras tradicionalmente consideradas de baixa produtividade, em terras férteis (FILHO et al, 2016). Já na última década vem sendo verificada uma forte expansão em áreas localizadas nos estados do Maranhão, Tocantins, Piauí e Bahia, região considerada a grande fronteira agrícola 
nacional da atualidade, sendo definida como Matopiba, e também em outras regiões na Amazônia (HECHT, 2005).

O gráfico 1 apresenta um comparativo, por Estado, de incrementos anuais de desmatamento no Bioma Cerrado, entre 2001 e 2017. Nota-se que os estados de Matopiba, Mato Grosso e Goiás lideram nas taxas de desmatamento. Já o estado de Minas Gerais apresentou anos com quedas significativas. Em números absolutos, entre 2001 e 2017 houve um incremento de 272.198,8 $\mathrm{Km}^{2}$ /ano de desmatamento do Bioma Cerrado (INPE, 2018).

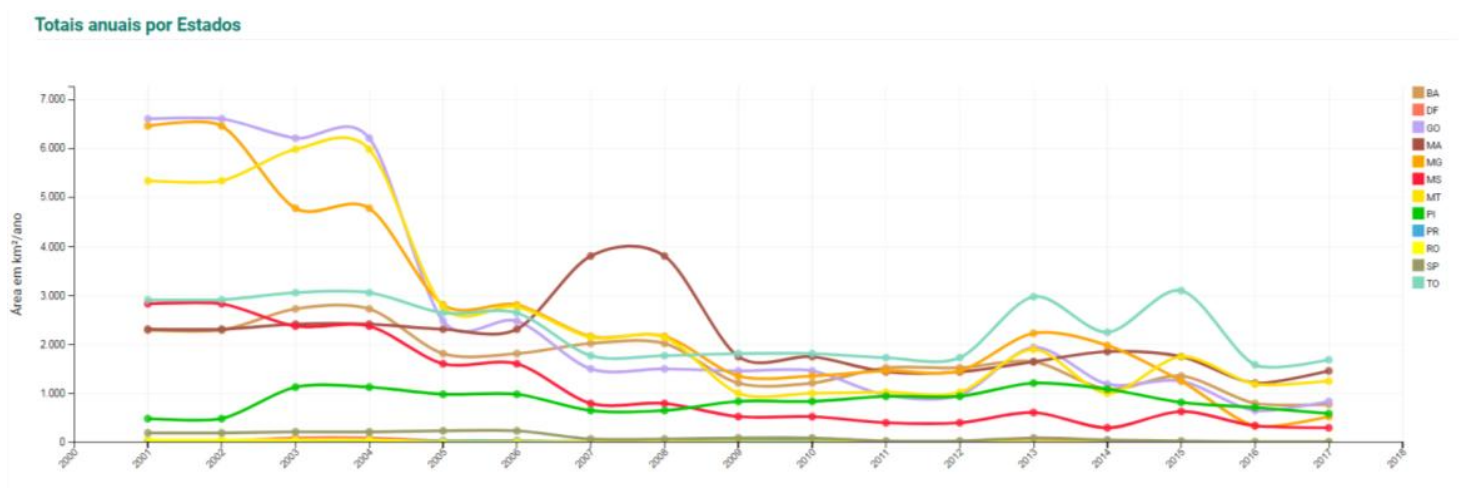

Gráfico 1 - Comparativo de incrementos de desmatamento no Cerrado por ano, entre 2001 e 2017.

Fonte: http://terrabrasilis.dpi.inpe.br/dashboard/deforestation/biomes/cerrado/increments/

Em relação ao Bioma da Amazônia, os dados disponibilizados pelo INPE de incremento anual de área desmatada são para o período de 1988 a 2018. Conforme o Gráfico 2, nota-se que houveram picos de desmatamento em 1995 e 2004, sobretudo nos estados do Mato Grosso, Pará e Roraima, que ainda lideram nos índices de desmatamento na Floresta Amazônica. Em números absolutos houve um incremento de $436.621 \mathrm{Km}^{2} /$ ano de desmatamento do Bioma Amazônico entre 1988 e 2018 (INPE, 2018). Como comparativo ao Cerrado, a Amazônia registrou no período entre 2001 e 2017 um incremento de $208.248 \mathrm{Km}^{2} /$ ano de desmatamento, em torno de $63.950 \mathrm{Km}^{2} /$ ano a menos que do Bioma Cerrado.

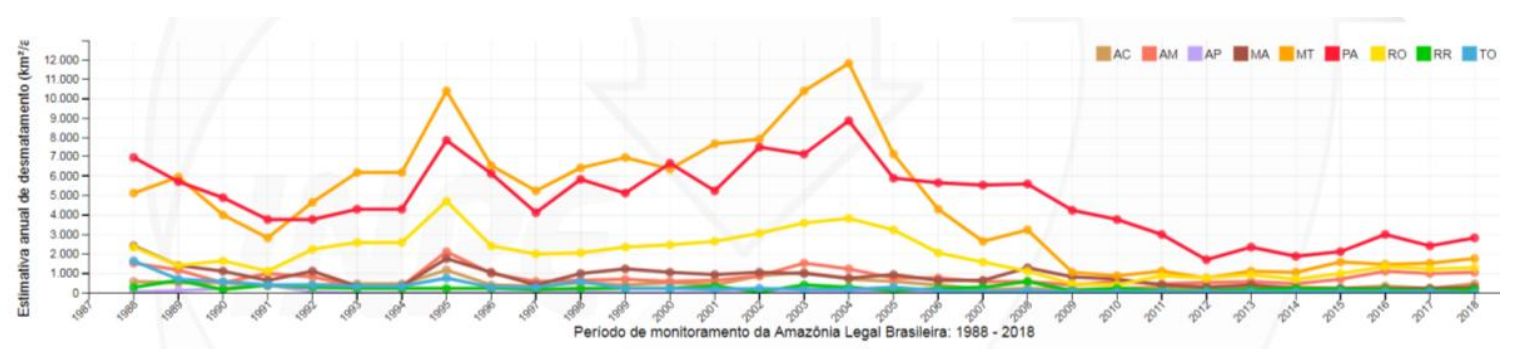

Gráfico 2 - Comparativo de incrementos de desmatamento Amazônia por ano, entre 1988 e 2018. Fonte: http://www.obt.inpe.br/prodes/dashboard/prodes-rates.html 
Esse processo de crescimento do agronegócio, a partir da expansão das fronteiras agrícolas, segue uma perspectiva global, já que em torno de $23 \%$ do crescimento da produção agrícola mundial ocorreu em função da expansão destas fronteiras (BANCO MUNDIAL, 2010).

Conforme Lourenço e Lima (2009), a expansão do agronegócio no Brasil se deve tanto as suas condições internas favoráveis, como de desenvolvimento e aplicação de novas tecnologias, disponibilidade de terras e mão de obra a baixo custo, quanto do contexto internacional, que apresenta dificuldades de reposição de produtos alimentícios e de agrocombustíveis. Em termos globais, conforme o relatório da OCDE/FAO (2017), o Brasil e a Argentina irão continuar registrando aumento de terras cultiváveis nos próximos dez anos, ao passo que em termos globais as áreas agrícolas utilizadas tenderão a diminuir (Gráfico 3).

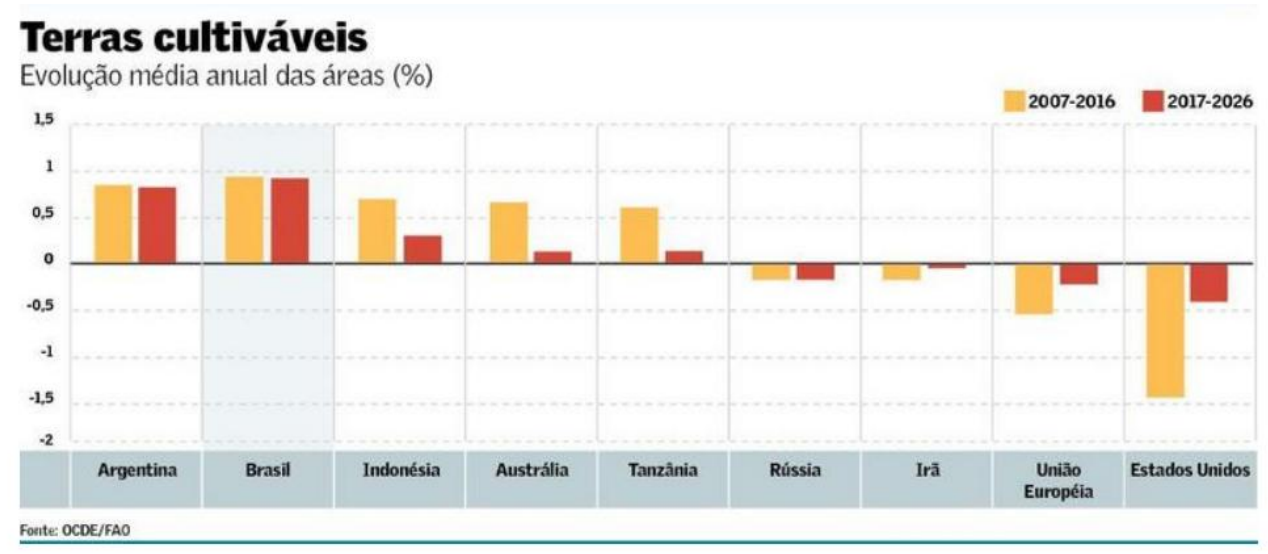

Gráfico 3 - Perspectivas Agrícolas para 2017 a 2018

Fonte: http://www.fao.org/3/a-i7465s.pdf

O plantio da soja no Brasil representa o principal produto em expansão. Atualmente, a soja ocupa 90\% (15,6 milhões de hectares) da agricultura do Cerrado, sendo que em 2013/2014 representava cerca de 52\% da soja cultivada no Cerrado. De 2000 a 2014, a área agrícola no bioma expandiu $87 \%$. O principal fator dessa mudança foi o cultivo da soja, que aumentou $108 \%$ nesse período. Em termos de área cultivada, foram 8,13 milhões de hectares nos estados de Mato Grosso e Goiás. Na região do Matopiba, a área cultivada de soja aumentou de 1 milhão para 3,4 milhões de hectares, um crescimento de $253 \%$ no período indicado (FILHO e COSTA, 2016). O aumento da produtividade da soja se deve, principalmente, a produção de sementes geneticamente modificadas. 
A maior parte da expansão agrícola na região do Matopiba ocorreu sobre vegetação nativa: 68\% (0,78 milhão de hectares) entre 2000 e 2007, e 62\% (1,3 milhão de hectares) entre 2007 e 2014, principalmente nos estados do Maranhão e no Piauí, que apresentam áreas pertencentes a atual fronteira agrícola no bioma. Com exceção de Mato Grosso, os estados que se encontram fora do Matopiba seguiram a tendência geral: 80\% (entre 2000-2007) e 89\% (entre 2007-2014) das mudanças ocorreram em área de pastagem ou outra agricultura. No Mato Grosso, em torno de $88 \%$ (entre 2000 e 2007) e 68\% (entre 2007 e 2014) avançaram sobre vegetação nativa (RUDORFF e RISSO, 2015; FILHO e COSTA, 2016).

Segundo a FAO, até 2025, a produção de soja passará de 89 milhões de toneladas, em média, para 136 milhões de toneladas (OCDE/FAO, 2017). Em termos de produção de grãos, o Ministério da Agricultura, Pecuária e Abastecimento (2017) aponta que a mesma deverá passar de 232,0 milhões de toneladas em 2016/2017 para 288,2 milhões de toneladas em 2026/27, indicando um acréscimo de 56,0 milhões de toneladas de grãos à produção atual brasileira.

Em termos de produção de carnes (bovina, suína e aves), estima-se que entre 2016/17 e 2026/27 a produção deverá aumentar em 7,5 milhões de toneladas, representando um acréscimo de 28,0\% em relação à produção de carnes de 2016/2017. As carnes de frango e suína são as que devem apresentar maior crescimento nos próximos anos, representando 33,4\% e 28,6\% respectivamente. Já a produção de carne bovina deverá aumentar 20,5\% entre o ano base e o final das projeções (MINISTÉRIO DA AGRICULTURA, PECUÁRIA E ABASTECIMENTO, 2017). A FAO estima que a participação do Brasil e dos EUA nas exportações totais de carne deverá aumentar para 44\%, respondendo por quase $70 \%$ do crescimento das vendas no mercado mundial. Além disso, o Brasil deverá se consolidar ainda mais na liderança da produção global de açúcar, representando $48 \%$ das exportações mundiais ao fim da próxima década (OCDE/FAO, 2017).

Conforme estimativas do Ministério da Agricultura, Pecuária e Abastecimento (2017), os produtos mais dinâmicos do agronegócio brasileiro deverão ser algodão em pluma, milho, carne suína, carne de frango, soja e grão. Entre as frutas, manga, uva e melão serão os destaques. O mercado interno e a demanda externa serão os principais fatores de crescimento para a maior parte desses produtos e, portanto, indicam também o maior potencial de crescimento da produção nos próximos dez anos. 
Nesse contexto, o Brasil é considerado por diversos especialistas o principal candidato ao posto de grande fornecedor alimentício global (LOURENÇO e LIMA, 2009). Assim, essa constatação torna os recursos naturais ${ }^{3}$ brasileiros um fator de competitividade.

\section{3 - O AGRONEGÓCIO E OS IMPACTOS AMBIENTAIS SOBRE OS RECURSOS NATURAIS}

A conversão de áreas florestadas em lavouras agrícolas representa uma mudança drástica no ecossistema original, já que gera alterações morfológicas, físicas, químicas e biológicas nos atributos do solo e, consequentemente, podem produzir impactos significativos, uma vez que os mecanismos naturais de reciclagem e de proteção do sistema são alterados (LIMA et al., 2011; LUIZÃO et al., 2006).

Pode-se dizer que os impactos ambientais causados pela atividade agropecuária nos recursos naturais são decorrentes da mudança do uso do solo, provocado pela supressão da vegetação natural e sua conversão em áreas cultivadas, da degradação do solo das áreas cultivadas, causada por práticas de manejo inadequadas (SAMBUICHI et al., 2012), e do uso indiscriminado de agrotóxicos e fertilizantes.

A erosão provocada pelo pisoteio do gado nas vertentes é uma das principais fornecedoras de sedimentos para os cursos d'água, pois altera a geometria das encostas, remove partículas do solo, induz e/ou intensifica a erosão laminar e em sulco e compacta o solo. É importante indicar que as pastagens degradadas apresentam altas taxas de perda de solo e água e baixa capacidade produtiva, tornando-as mais vulneráveis aos ataques de pragas, doenças e plantas invasoras.

A degradação de extensas áreas cultivadas e de pastagem aumenta a demanda por novas terras, pois o custo de desmatar para incorporar novas fronteiras agropecuárias é geralmente muito menor que o de recuperar áreas degradadas e improdutivas. Os dados da FAO (2015) indicam que 33\% das terras agricultáveis do mundo estão degradadas, com perdas anuais de aproximadamente 25 a 40 bilhões de toneladas de solos, reduzindo significativamente a produtividade das culturas agrícolas e a capacidade do solo de armazenar carbono, nutrientes e água. As principais causas são a erosão, salinização, compactação, acidificação e contaminação.

\footnotetext{
3 Recurso Natural: a definição de recurso natural se refere à função que determinado elemento natural oferece, apresentando, portanto, caráter utilitário (Zimmermann, 1957). Assim, a noção circunscrita ao conceito "recursos", ou seja, elemento natural a que foi conferido valor, é socialmente construída e está atrelada aos níveis de produtividade, que por sua vez se modificam conforme a sua apropriação por determinados grupos de poder (Bisogni, 2008).
} 
Tais aspectos influenciam diretamente a disponibilidade de recursos naturais para a produção de alimentos.

O uso excessivo de agrotóxicos na agricultura vem sendo considerado um importante agente de contaminação do solo, das águas e do ar devido à sua toxicidade, sua permanência no solo e o crescente aumento de seus teores encontrados no ambiente (OLIVEIRA et al., 2006; SILVÉRIO et al., 2012). Estima-se que apenas 30\% do total de agrotóxico permanecem na planta. Os efeitos negativos desses produtos nos ecossistemas naturais e cultivados incluem, além da contaminação do ambiente, a alteração da microbiologia do solo, a morte de polinizadores e de organismos que controlam as populações de pragas e prejuízos às lavouras (PINHEIRO e FREITAS, 2010). Os fertilizantes químicos, se aplicados intensivamente, também causam impactos significativos no ambiente, podendo levar à eutrofização de cursos d'água, lagos e mananciais, acidificação dos solos, contaminação de aquíferos, geração de gases associados ao efeito estufa e destruição da camada de ozônio (SAMBUICHI et al., 2012).

Assim, os impactos gerados nos solos podem provocar impactos nas águas superficiais e subsuperficiais e, estas, por sua vez, podem afetar a fauna e os seres humanos. De acordo com Silvério et al., (2012), o consumo dessas águas ou suas reutilizações na agricultura podem resultar em riscos à saúde pública, além da contaminação de recursos naturais. Dessa forma, a permanência, a intensidade e os riscos desses impactos sobre os recursos naturais e a biodiversidade, ao longo do tempo, precisam ser mais pesquisados. 
A expansão do agronegócio no Brasil se distancia de caminhos que visam à sustentabilidade dos recursos naturais, em função das suas atividades provocarem a degradação física e a contaminação do solo, por meio de manejos intensivos e uso indiscriminado de agrotóxicos e fertilizantes, que podem comprometer a qualidade das águas dos sistemas hídricos, incluindo mananciais, nascentes e as águas subterrâneas.

No Brasil, existem poucos dados sobre a quantidade total de terras degradadas. O Censo Agropecuário (IBGE, 2006) apresentou que haveria 9,8 milhões de hectares de pastagens degradadas e 0,7 milhão de hectares de terras degradadas erodidas, desertificadas ou salinizadas nos estabelecimentos rurais. Contudo, esses dados não incluem as terras degradadas e abandonadas que não constam nos estabelecimentos agropecuários recenseados. Dessa forma, seguramente esses números estão subestimados (SAMBUICHI et al., 2012).

Em geral, os solos tropicais são mais suscetíveis à degradação que os solos de clima temperado. $\mathrm{O}$ uso do fogo indiscriminadamente na abertura de áreas, técnica bastante difundida principalmente no Cerrado e na Floresta Amazônica, provoca, entre outros impactos, a perda dos agregados de matéria orgânica e argila. Esses solos, quando submetidos ao manejo intensivo por períodos prolongados, têm a sua estrutura alterada, contribuindo para sua erosão, compactação e degradação (PRIMAVESI, 1990). Já as práticas de conservação do solo, como de plantio direto, plantio em curvas de nível e rotação de culturas são indicadas para evitar a degradação dos solos. A implementação dessas práticas, apesar de ainda pouco representativa no Brasil, varia conforme a região do país. Enquanto a região Sul apresenta maior percentual de utilização de práticas de conservação do solo, as regiões Norte e Nordeste apresentam maior percentual de uso de queimadas (SAMBUICHI et al., 2012).

Em relação ao uso de agrotóxicos e fertilizantes, seu consumo no Brasil aumentou nos últimos anos, principalmente em função da tecnificação e intensificação dos cultivos, e menos pelo aumento da área cultivada. Conforme o Sindicato Nacional da Indústria de Produtos para Defesa Agrícola (SINDAG), no período entre 2004 e 2008, por exemplo, observou-se o crescimento de 4,6\% da área cultivada, ao passo que as quantidades vendidas de agrotóxicos, no mesmo período, subiram aproximadamente 44,6\%. Somente no ano de 2009 foram comercializadas 800,2 toneladas desses produtos (IPEA, 2011a). Atualmente, o valor total das vendas de agrotóxicos no Brasil chega a US \$ 8,5 bilhões/ano, formando o maior mercado de agrotóxicos do mundo (SANTOS, 2012).

Salienta-se que o crescimento das exportações de soja, milho e algodão no Brasil foi alavancado, sobretudo, pelo desenvolvimento de sementes e plantas geneticamente modificadas, 
que foram liberadas de forma mais consistente com a Lei de Biossegurança ${ }^{4}$, em 2005. Após a definitiva liberação do cultivo de transgênicos, o país obteve, segundo dados do Serviço Internacional para a Aquisição de Aplicações em Agrobiotecnologia, o maior aumento nominal registrado em culturas de transgênicos no mundo (GOMES e BÓREM, 2013). O Gráfico 3 mostra que, de 2004 a 2005, houve uma redução abrupta no incremento anual da área desmatada no Cerrado, provavelmente em função do aumento da produtividade com a liberação de transgênicos pela Lei de Biossegurança.

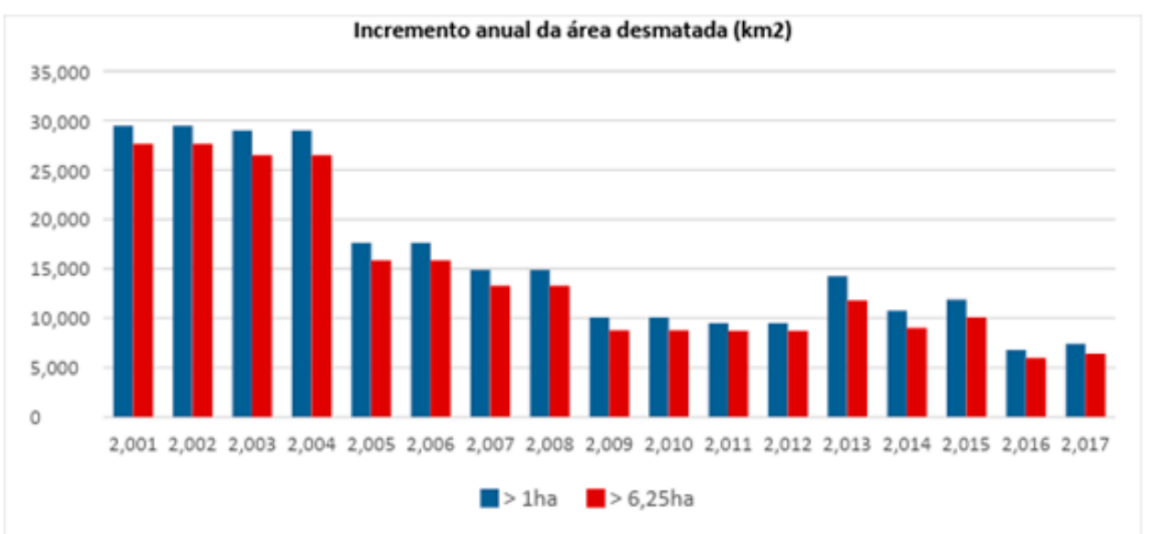

Gráfico 3 - Comparativo do desmatamento no Bioma Cerrado por ano, entre 2001 e 2017.

Fonte: http://www.ccst.inpe.br/inpe-divulga-dados-sobre-o-desmatamento-do-bioma-cerrado/

De acordo com o Ministério do Meio Ambiente, o cultivo de plantas transgênicas, em larga escala, poderá provocar efeitos difíceis de estimar ou até mesmo irreversíveis, particularmente sobre os componentes da biodiversidade. Além disso, o Ministério ainda destaca os demais riscos já comprovados no solo e na água, onde ainda não há previsibilidade dos possíveis efeitos.

Nesse sentido, observa-se que o avanço da tecnologia empregada na agropecuária nos últimos anos não considerou os impactos ambientais e estimulou o consumo de agroquímicos no país, a exemplo da tecnologia dos transgênicos, com o desenvolvimento da soja resistente a herbicidas (SAMBUICHI et al., 2012). Sabe-se que o uso de agrotóxicos utilizados no controle de pragas em monoculturas está perdendo eficiência. Nesse modo de cultivo, a única forma de controlar as pragas é por meio dos agrotóxicos. Contudo, continuamente são produzidas populações resistentes a algum tipo de agrotóxico, sendo necessário usar quantidades

\footnotetext{
4 A Lei de Biossegurança, Lei $n^{\circ}$ 11.105, de 24 de março de 2005, estabelece normas de segurança e mecanismos de fiscalização sobre a construção, o cultivo, a produção, a manipulação, o transporte, a transferência, a importação, a exportação, o armazenamento, a pesquisa, a comercialização, o consumo, a liberação no meio ambiente e o descarte de organismos geneticamente modificados - OGM e seus derivados.
} 
cada vez maiores de agrotóxicos, ou produzir novos produtos químicos mais tóxicos e ou ainda desenvolver sementes transgênicas resistentes a determinadas pragas. Conforme Folgado (2014), as sementes transgênicas só aumentaram o uso indiscriminado do agrotóxico, pois a maioria das plantas geneticamente modificadas será resistente a algum tipo de agrotóxico. Desse modo, podemos constatar que com o uso das sementes transgênicas no país o uso de agrotóxicos aumentou consideravelmente (FOLGADO, 2014). Se por um lado o solo e as águas estão cada vez mais impactados, por outro o agronegócio criou para si um mercado econômico extremamente vantajoso, pois atua concomitantemente na produção de sementes transgênicas e de insumos agrícolas.

Atualmente, o uso de agrotóxicos no Brasil é visto como um dos principais responsáveis pela degradação ambiental devido à contaminação dos recursos naturais (CASTOR, 2016). Conforme o IBGE (2011), a contaminação dos cursos d'água por produtos agroquímicos no País perde apenas pela poluição por esgoto.

\section{4 - AVANÇOS NECESSÁRIOS}

Para uma corrente de pensamento, o aumento da produção agrícola, associado à preservação dos recursos naturais, só é viabilizado mediante o desmatamento de novas áreas, a intensificação das áreas cultivadas e a proteção das áreas naturais remanescentes (TILMAN et al., 2011). Contudo, pesquisas vêm mostrando que a efetividade desse modelo de conservação das áreas naturais depende da qualidade da intensificação tecnológica empregada nos cultivos agrícolas (BAULCOMBE et al., 2009). Proteger as áreas naturais nas propriedades rurais apenas com base nas leis do Código Florestal $1^{5}$ e do $\mathrm{SNUC}^{6}$ não é suficiente se a qualidade ambiental das áreas cultivadas do entorno estiver comprometida pelo uso de tecnologias inadequadas. Além disso, a conservação dos recursos hídricos, por exemplo, depende da condição ambiental dos solos nas bacias hidrográficas. Assim, mesmo que sejam mantidas áreas de vegetação natural protegidas conforme a legislação, se a maior parte do solo da bacia estiver degradada e contaminada devido ao manejo inadequado das áreas cultivadas, a vazão e a qualidade ambiental dos corpos d'água serão afetadas (SAMBUICHI et al., 2012).

A conservação da biodiversidade também depende fundamentalmente das condições do meio ambiente. Conforme Laurence et al. (2012), pesquisadores vêm enfatizando que, para

\footnotetext{
5 O Código Florestal, Lei 12.651, de 25 de maio de 2012, estabelece normas gerais sobre a Proteção da Vegetação Nativa, incluindo Áreas de Preservação Permanente, de Reserva Legal e de Uso Restrito; a exploração florestal, o suprimento de matéria-prima florestal, o controle da origem dos produtos florestais, o controle e prevenção dos incêndios florestais, e a previsão de instrumentos econômicos e financeiros para o alcance de seus objetivos.

${ }^{6}$ O Sistema Nacional de Unidades de Conservação (SNUC), Lei 9.985 de 18 de julho de 2000, estabelece critérios e normas para a criação, implantação e gestão das unidades de conservação.
} 
evitar o colapso de biodiversidade das áreas naturais protegidas, especialmente nas regiões de clima tropical, é necessário atentar para as condições do entorno. A intensificação tecnológica convencional, através da monocultura e do uso intensivo de agrotóxicos e fertilizantes, tem tornado as áreas cultivadas inviáveis às espécies, isolando os remanescentes de vegetação nativa, os quais, fragmentados, perdem biodiversidade e se degradam com o tempo. Assim, mesmo se fossem reutilizadas pelo agronegócio todas as áreas já desmatadas atualmente, haveria uma progressiva degradação dos recursos naturais e perda dos serviços ambientais, provocando a longo prazo a redução da produção agrícola (SAMBUICHI et al., 2012).

Nesse sentido, os custos ambientais decorrentes da forma de produção e expansão do agronegócio precisam ser incorporados nas transações financeiras, para assim, demonstrar e avaliar economicamente as perdas ambientais e se é realmente vantajoso manter a lógica de funcionamento do agronegócio.

Para controlar os impactos ambientais decorrentes do agronegócio é necessário adotar práticas de manejo sustentáveis, investindo em métodos que envolvam a diversificação e a rotação de culturas, bem como o uso de insumos agrícolas alternativos e pouco agressivos para o controle de pragas (PERFECTO e VANDERMEER, 2010). Se esses sistemas de produção de baixo impacto ambiental forem bem executados, as técnicas podem ser difundidas para as áreas atualmente degradadas e com baixa produção. Para Sambuichi et al. (2012), o melhor aproveitamento dessas terras já seria suficiente para atender às necessidades de aumento da produção agropecuária sem precisar desmatar novas áreas para cultivo, e possivelmente maior seria a interconexão entre as áreas cultivadas e as áreas remanescentes de vegetação nativa adjacentes. 


\section{5 - CONSIDERAÇÕES FINAIS}

Pode-se dizer que o processo de modernização e expansão do setor agropecuário no Brasil impulsionou a sua produtividade, no entanto, provocou impactos negativos para o meio ambiente, tais como a erosão e contaminação dos solos, do ar e das águas. A maioria das monoculturas utilizam técnicas convencionais de cultivo, que ao longo do tempo degradam os solos. Além disso, o uso intensivo de agrotóxicos tende a se acumular no solo e na biota e seus resíduos podem contaminar às águas superficiais e subterrâneas.

Assim, embora a expansão do agronegócio seja a base da economia brasileira, os efeitos da sua utilização gera impactos nos recursos naturais, que podem ser irremediáveis a longo prazo. Esses efeitos deveriam ser considerados nos custos da operação do agronegócio, pois afetam diretamente os recursos naturais, reduzindo a biodiversidade e os serviços ambientais disponibilizados por eles.

A intensificação tecnológica não pode considerar apenas a produtividade e o retorno econômico em curto prazo. Ela precisa desenvolver-se em bases ecológicas, visando à otimização e à sustentabilidade da produção agropecuária em seu ambiente ao longo do tempo. Dessa forma, é inadiável repensar o modelo de desenvolvimento tecnológico que vem sendo adotado pelo agronegócio brasileiro, como investindo em métodos que envolvam a diversificação e a rotação de culturas, bem como o uso de insumos agrícolas alternativos e pouco agressivos para o controle de pragas.

\section{REFERÊNCIAS BIBLIOGRÁFICAS}

ASSAD, E. D.; MARTINS, S. C.; PINTO, H. P. (2012). Sustentabilidade no agronegócio brasileiro. Rio de Janeiro: Fundação Brasileira para o Desenvolvimento Sustentável.

BANCO MUNDIAL. Rising global interest in farmland: Can it yield sustainable and equitable benefits? Washington D.C., 07 de setembro de 2010.

BAULCOMBE, D. et al. Reaping the benefits: science and the sustainable intensification of global agriculture. London: The Royal Society, 2009.

BIALOSKORSKI NETO, S. Agribusiness cooperativo: Economia, doutrina, e estratégias de gestão. Piracicaba: ESALQ/USP, 1994.

BISOGNI, F.M. Manejo e Gestão de Recursos Naturais, Certificação Ambiental e Impactos Ambientais Associados. Um estudo de caso sobre atividade florestal de cultivo de pinus. 2008. Monografia de Bacharelado do Curso de Geografia. Universidade Estadual de Londrina.

BRASIL. Lei $\mathbf{n}^{\mathbf{0}} \mathbf{1 2 . 6 5 1}$, de 25 de maio de 2012. Dispõe sobre a proteção da vegetação nativa e dá outras providências. Diário Oficial da República Federativa do Brasil, Brasília, DF, 28 maio 2012. 
BRASIL. Lei $\mathbf{n}^{\mathbf{0}} \mathbf{1 1 . 1 0 5}$, de 24 de março de 2005. Estabelece normas de segurança e mecanismos de fiscalização de atividades que envolvam organismos geneticamente modificados - OGM e seus derivados.

BRASIL. Lei 9.985 de 18 de julho de 2000. Institui o Sistema Nacional de Unidades de Conservação (SNUC), estabelece critérios e normas para a criação, implantação e gestão das unidades de conservação.

CASTOR, A.B.C. Uso de agrotóxicos e o direito ao meio ambiente ecologicamente equilibrado. Monografia apresentada ao Departamento de Direito da Pontifícia Universidade Católica do Rio de Janeiro (PUCRio) para a obtenção do Título de Bacharel em Direito. 2016.

CONTINI, E. et al. Evolução recente e tendências do agronegócio. Revista de política agrícola, Brasília, Jan./ Fev./Mar. 2006.

FAO. Status of the World's Soil Resources | Main Report. 2015 Disponível em < http://www.fao.org/3/a-i5199e.pdf>. Acessado em: 18 de novembro de 2018.

FILHO, A.C; COSTA, K.. A expansão da soja no cerrado. Caminhos para a ocupação territorial, uso do solo e produção sustentável. Agroicone, Input. 2016.

FILHO, R.V; GASQUES, J.G; CARVALHO, A.X.Y[et al.]. Agricultura, transformação produtiva e sustentabilidade. - Brasília IPEA, 2016. 391 p. Disponível em < http://www.ipea.gov.br/agencia/images/stories/PDFs/livros/livros/160725_agricultura_transf ormacao_produtiva.pdf $>$ Acessado em 10 de novembro de 2018.

FOLGADO, C.A.R. Agrotóxicos: um problema invisibilizado. Movimento dos pequenos agricultores. Brasília - Distrito Federal, Abril de 2014. 2014.

GAZZONI, D.L. A sustentabilidade da soja no contexto do agronegócio brasileiro e mundial. - Londrina: Embrapa Soja. 2013. Disponível em < https://www.infoteca.cnptia.embrapa.br/bitstream/doc/973921/1/Doc344online.pdf> Acessado em 15 de novembro de 2018

GOMES, W.S; BORÉM, A. Biotecnologia: novo paradigma do agronegócio brasileiro. REA. Revista de economia e agronegócio. Revista de economia e agronegócio. Vol.11, $\mathrm{n}^{\circ} 1$. 2013. Disponível em < https://www.revistarea.ufv.br/index.php/rea/article/view/215> Acessado em 20 de novembro 2018.

HECHT, S. B. Soybeans, development and conservation on the Amazon frontier. Development and Change, Institute of Social Studies, v. 36, n. 2, p. 375-404, 2005.

IBGE - INSTITUTO BRASILEIRO DE GEOGRAFIA E ESTATÍSTICA. Censo agropecuário - 2006. 2006. Disponível em <https://sidra.ibge.gov.br/Acervo\#/S/CA/A/Q > Acesso em 24 de novembro 2018.

IBGE. Atlas de Saneamento. 2011. Disponível em < https://ww2.ibge.gov.br/home/estatistica/populacao/atlas saneamento/default zip.shtm >.

Acessado em 10 de novembro 2018. 
IPEA - INSTITUTO DE PESQUISA ECONÔMICA APLICADA. Desenvolvimento rural. Políticas sociais: acompanhamento e análise, Brasília: Diretoria de Políticas Sociais/Ipea, 2011a. v. 19. cap. 7, p. 231-286.

INPE. Incrementos de desmatamento anuais no Cerrado Brasileiro. 2018. Disponível $<$ http://terrabrasilis.dpi.inpe.br/dashboard/deforestation/biomes/cerrado/increments/>.

Acessado em 13 de novembro de 2018.

INPE. Incrementos de desmatamento anuais na Amazônia Brasileira. 2018. Disponível em:

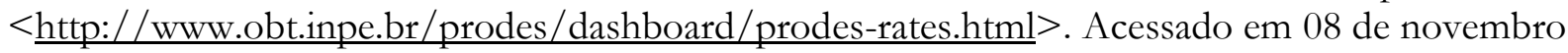
de 2018.

LAURENCE, W. F. et al. Averting biodiversity collapse in tropical forest protected areas. Nature, n. 11.318, 2012. Published online.

LIMA, S.S et al. Atributos químicos e estoques de carbono e nitrogênio em argissolo vermelho-amarelo sob sistemas agroflorestais e agricultura de corte e queima no norte do Piauí. Rev. Árvore vol.35 no.1 Viçosa Jan./Feb. 2011.

LOURENÇO, J.C; LIMA, C.E.B. Evolução do agronegócio brasileiro, desafios e perspectivas. In: Observatório de la Economía Latinoamericana, $\mathrm{n}^{\circ}$ 118. 2009. Disponível em http://www.eumed.net/cursecon/ ecolat/br/. Acessado em 01/11/2018.

LUIZÃO, F. J. et al. (Eds). Sistemas Agroflorestais: bases para o desenvolvimento sustentável. Campos dos Goytacazes: Universidade Estadual do Norte Fluminense Darcy Ribeiro, 2006. p.87-100.

MINISTÉRIO DA AGRICULTURA, PECUÁRIA E ABASTECIMENTO. Projeções do Agronegócio: Brasil 2016/17 a 2026/27 - Projeções de Longo Prazo. $8^{a}$ edição. Ano 2017. Disponível em: < http://www.agricultura.gov.br/assuntos/politica-agricola/todas-publicacoesde-politica-agricola/projecoes-do-agronegocio/projecoes-do-agronegocio-2017-a-2027-versaopreliminar-25-07-17.pdf $>$ Acessado em 01/11/2018.

MINISTÉRIO DO MEIO AMBIENTE. Disponível em: < http://www.mma.gov.br/informma/item/7511-riscos.html >. Acessado em 13/11/2018.

OCDE/FAO (2017), OCDE-FAO Perspectivas Agrícolas 2017-2026, Éditions OCDE, París. 2017. Disponível em: < http://dx.doi.org/10.1787/agr_outlook-2017-es>. Acessado em $12 / 11 / 2018$.

OLIVEIRA, E.; MAGGI, M.F.; MATOS, E.; RAMOS, M.S.; VAGNER, M.W.; LOPES, E.C. (2009) Technology of application of defensives and relations with the risk of contamination of the water and soil. Pesquisa Aplicada \& Agrotecnologia, v. 2, n. 3, p. 161-169

PLATA, L. E. A.; CONCEIÇÃO, A. V. O agronegócio brasileiro: análise das principais commodities. Disponível em <http://www.centropaulasouza.sp.gov.br/ posgraduacao/workshop-de-pos-graduacao-e-pesquisa/007-workshop-2012/workshop/

trabalhos/gestneg/o-agronegocio-brasileiro.pdf>. 2015. 
PERFECTO, I.; VANDERMEER, J. The agroecological matrix as alternative to the landsparing/agriculture intensification model. PNAS, v. 107, n. 13, p. 5.786-5.791, 2010.

PINHEIRO, J. N.; FREITAS, B. M. Efeitos letais dos pesticidas agrícolas sobre polinizadores e perspectivas de manejo para os agroecossistemas brasileiros. Oecologia australis, v. 14, n. 1, p. 266-281, 2010.

PRIMAVESI, A. Manejo ecológico do solo: a agricultura em regiões tropicais. 9. ed. São Paulo: Nobel, 1990.

ROBERTS, T. L.; RYAN, J. Solo e Segurança Alimentar. Piracicaba: International Plant Nutrition Institute, 2015. 3p. (Informações agronômicas, No 150).

RUDORFF, B.; RISSO, J. et al. Agrosatélite Geotecnologia Aplicada Ltda. Análise Geoespacial da Dinâmica das Culturas Anuais no Bioma Cerrado: 2000 a 2014. Florianópolis, Santa Catarina, Brasil, 2015.

SAMBUICHI, R.H.R; OLIVEIRA, M.A.C; SILVA, A.P.M; LUEDEMANN, G. A sustentabilidade ambiental da agropecuária brasileira: impactos, políticas públicas e desafio. Instituto de Pesquisa Econômica Aplicada. IPEA. 2012.

SANTOS, G. R. Características, sistema de registros de produtos e concorrência no mercado de agrotóxicos no Brasil. Radar: tecnologia, produção e comércio exterior, n. 20, p. $07-17,2012$.

SILVÉRIO, F.O.; SILVA, J.G.S.; AGUIAR, M.C.S.; CACIQUE, A.P.; PINHO, G.P. (2012) Análise de agrotóxicos em água usando extração líquido-líquido com partição em baixa temperatura por cromatografia líquida de alta eficiência. Química Nova, v. 35, n. 10, p. 2052-2056.

TILMAN, D. et al. Global food demand and the sustainable intensification of agriculture. PNAS, v. 108, n. 50, p. 20.260-20.264, 2011.

ZIMMERMANN, E.W. (1966) Introducción a los recursos mundiales.Barcelona: OikosTau. 